\title{
SISTEM INFORMASI INDEKOS BERBASIS WEB
}

\author{
Rinto Suppa ${ }^{1)}$, Tizam Saldi' ${ }^{2)}$ \\ 1) Dosen Program Studi Teknik Informatika, Universitas Andi Djemma, Palopo \\ ${ }^{2)}$ Program Studi Teknik Informatika Universitas Andi Djemma \\ ${ }^{1)}$ rintosuppa@gmail.com \\ 2)
}

\begin{abstract}
Abstrak
Sistem informasi indekos berbasis web dibuat bertujuan untuk mendukung masyarakat dalam mengakses informasi indekos yang cepat dan lebih efisien. Sistem ini juga dapat membantu pencari indekos dalam mencari indekos sesuai keinginan tanpa harus mendatangi indekos secara langsung dan juga memudahkan buat para pemilik indekos dalam memasarkan indekosnya secara mudah. Metode pengumpulan data yang digunakan dalam penelitian ini dengan cara observasi, wawancara, dan studi pustaka. Observasi ditempuh dengan cara melakukan pengamatan secara langsung terhadap indekos, wawancara kegiatan tanya jawab dengan orang yang berhubungan dengan objek penelitian, dan studi pustaka teknik mengumpulkan data dengan bahan rujukan buku dan dokumen yang berhubungan langsung dengan penelitian. Sistem informasi indekos berbasis web ini menggunakan teknik pengembangan sistem UML (Unifed Modeling Languange) yang terdiri dari use case diagram, activity diagram, sequence diagram, dan class diagram, bahasa pemrograman PHP, dan database MySQL. Sistem ini terdiri dari tiga aktor yaitu admin, pemilik indekos, dan pencari indekos. Hasil dari sistem ini pencari indekos dapat mencari indekos berdasarkan kategori, wilayah dan harga, pemilik indekos dalam memasarkan indekosnya terlebih dahulu harus melakukan registrasi agar bisa menginput data indekosnya, admin dapat mengelola data indekos dan data user. Sistem ini telah dibuat dan terkomputerisasi secara online.
\end{abstract}

Kata Kunci: Sistem Informasi, Indekos, Web, UML, PHP, MySQL.

\section{PENDAHULUAN}

Seiring dengan berkembangnya teknologi informasi, kemajuan dalam mencari informasi sudah sangat mudah, salah satunya menggunakan media internet yang sudah menjadi trend masa kini. Dengan praktisnya internet saat ini sudah menjadi suatu kebiasaan bagi kalangan orang-orang yang suka mencari suatu informasi secara cepat. Kurangnya informasi indekos membuat calon penghuni indekos kesulitan dalam mencari indekos yang layak dan sesuai dalam waktu yang cepat. Indekos sendiri memiliki berbagai tipe kamar di mulai dari ukuran, kelengkapan kamar, dan fasilitas. Harga sewa indekos pada umumnya berdasarkan fasilitas, semakin lengkap fasilitas kamar dan letak indekos tersebut maka semakin mahal harga sewanya. Cara yang biasanya dilakukan dalam mencari indekos ialah bertanya pada warga sekitar, mendapat informasi dari teman atau saudara, atau mencari indekos terdekat di daerah sekolah, kampus, ataupun tempat kerja.

Sistem ini menyediakan informasi indekos mulai dari informasi tempat, foto indekos, harga, dan fasilitas semua tersedia di sistem ini. Sebelumnya memang sudah ada penelitian seperti ini, namun yang membedakan penelitian penulis dengan penelitian terdahulu adalah penelitian terdahulu hanya terpusat dengan satu kota atau satu kawasan saja sedangkan pada penelitian penulis ini tidak terpusat dengan hanya satu kota saja atau satu kawasan saja. Dengan adanya sistem informasi indekos berbasis web diharapkan dapat bermanfaat bagi masyarakarat yang mencari indekos dan para pemilik indekos dalam memasarkan indekosnya. 


\section{METODOLOGI PENELITIAN}

Lokasi penelitian pada pembahasan dan penyusunan skripsi ini adalah di Kota Palopo. Adapun waktu penelitian yang digunakan kurang lebih 3 bulan. Teknik pengumpulan data yang digunakan dalam penelitian ini terdiri dari tiga cara yaitu, (1) observasi; (2) wawancara; dan (3) studi pustaka. Metode pengembangan sistem yang digunakan ialah UML (Unified Modeling Language) yang terdiri dari yang terdiri dari use case diagram, activity diagram, sequence diagram, dan class diagram. Diagram alir penelitian ditunjukan pada gambar 1 berikut.

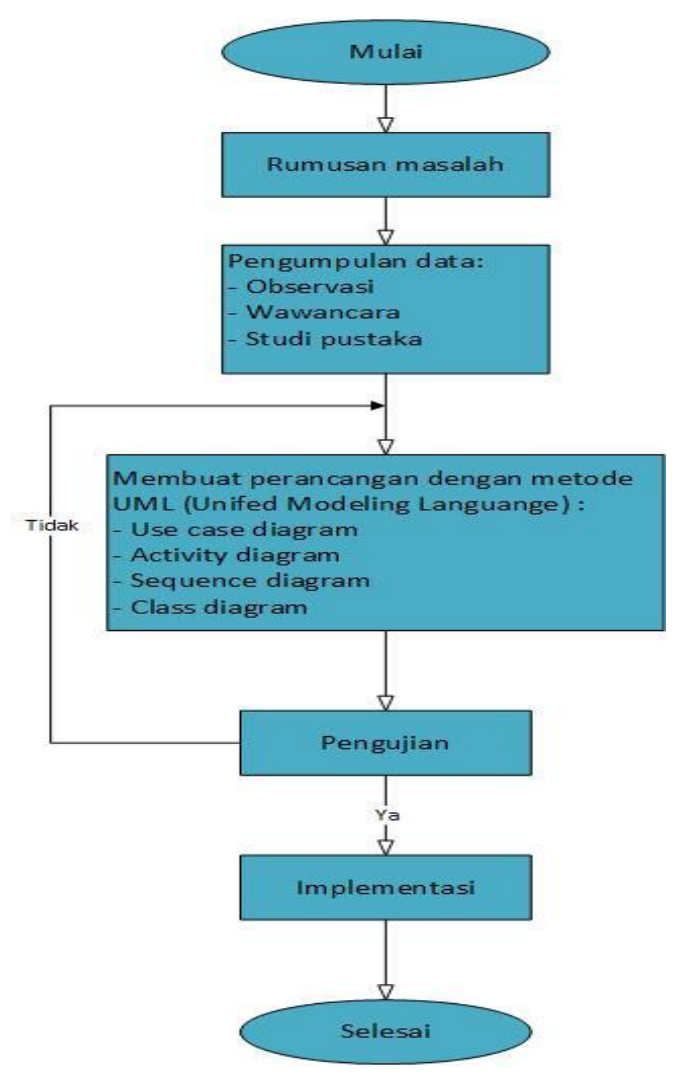

Gambar 1. Diagram Alir Penelitian

\section{HASIL DAN PEMBAHASAN}

Pengembangan sistem informasi Indekos di Kota Palopo ini diawali dengan analisis kebutuhan system dan penumpulan data. Berdasarkan hasil pengumpulan data yang telah dianalisis dibutuhkan sebuah sistem informasi indekos di Kota Palopo yang efektif dan efisen baik dalam hal mencari indekos atau memperkenalkan usaha indekos itu sendiri. Langkah selanjutnya adalah perancangan sistem dengan menggunakan UML, database (basis data), dan user interface (tampilan). 


\section{Perancangan Unified Modeling Language (UML)}

\section{Use Case Diagram Login System}

Use case digram login system merupakan bagian dari metodologi pengembangan, suatu perangkat lunak yang dilakukan setelah melalui tahap analisis. Padas item informasi ini menggambarkan tentang admin, pemilik indekos, dan pencari indekos dalam menjalankan tugasnya.

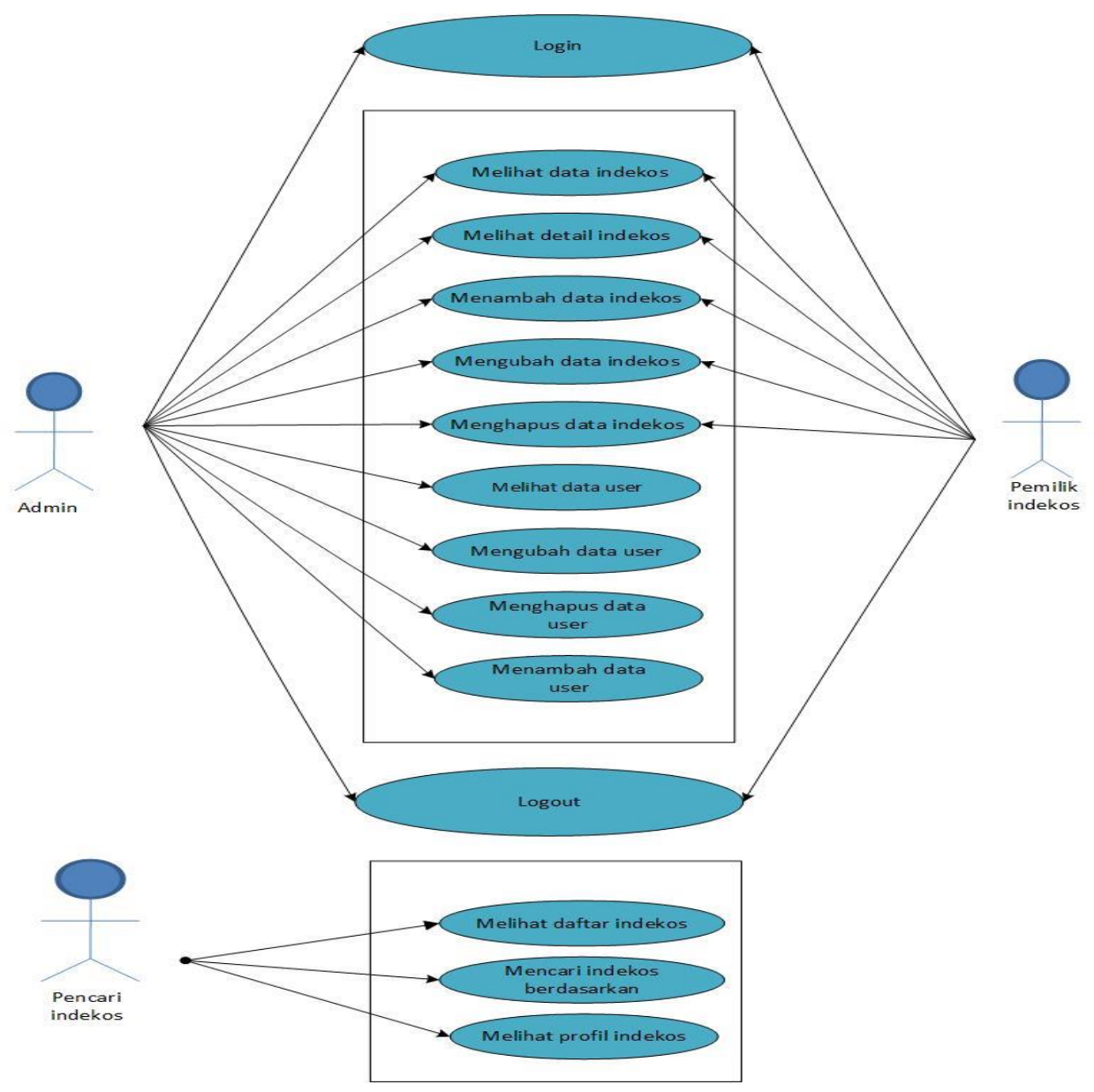

Gambar 2. Use Case Diagram Login System

\section{Activity Diagram Login System}

Activity diagram Login System menggambarkan aktivitas diagram yang berjalan pada sistem aplikasi seperti yang terlihat pada gambar dibawah ini: 


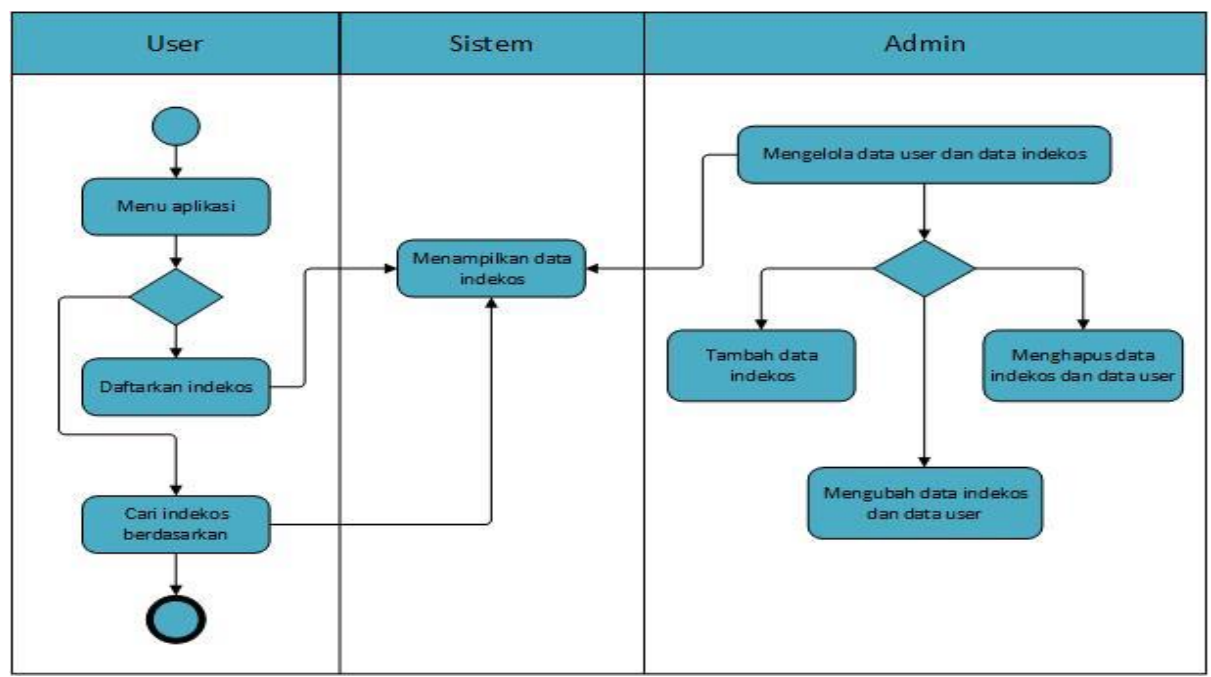

Gambar 3. Activity Diagram Login System

\section{Class Diagram}

Class diagram menggambarkan struktur dan hubungan antar objek-objek yang ada pada sistem.

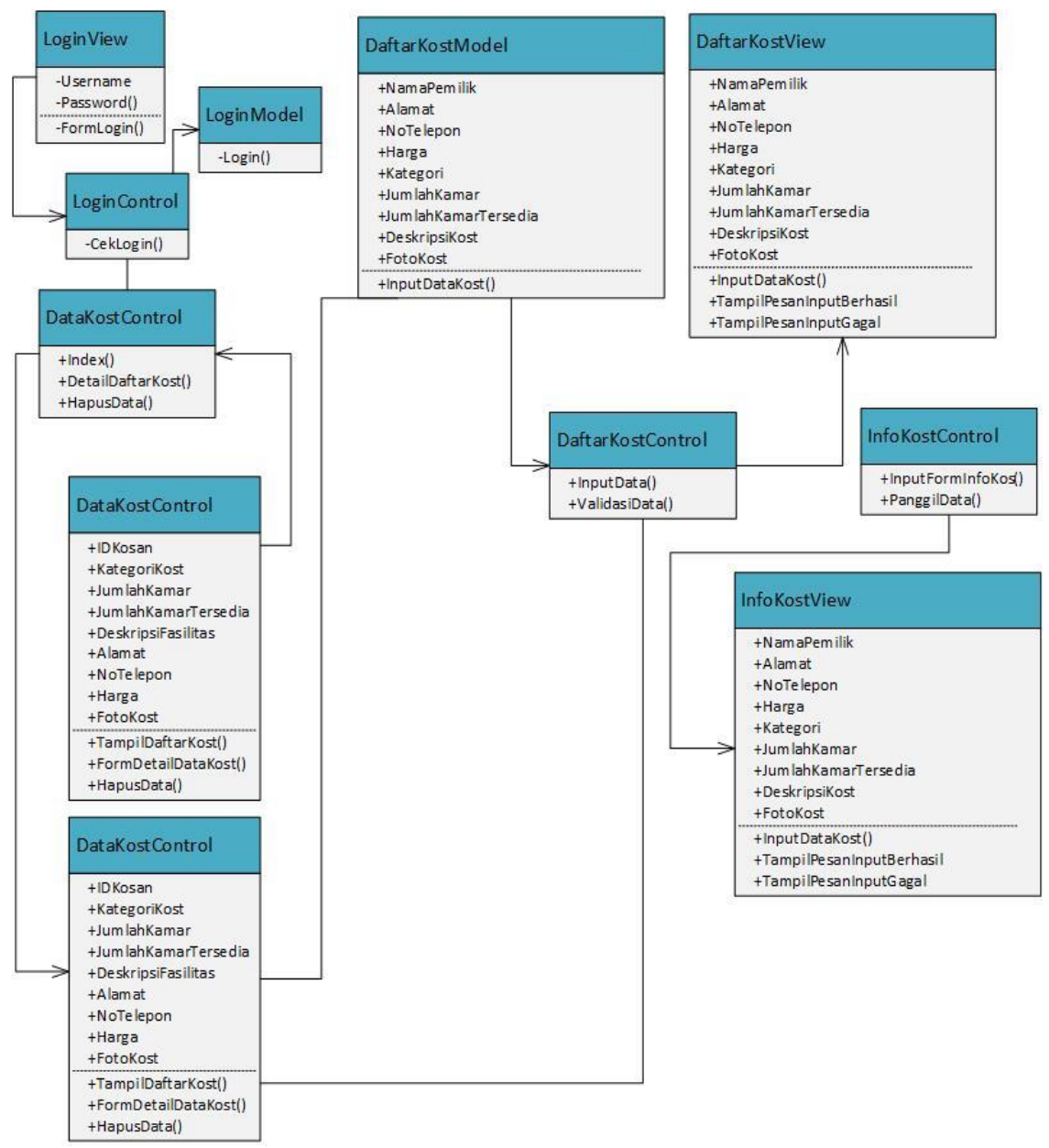

Gambar 4. Class Diagram 


\section{Implementasi Sistem}

a) Halaman home

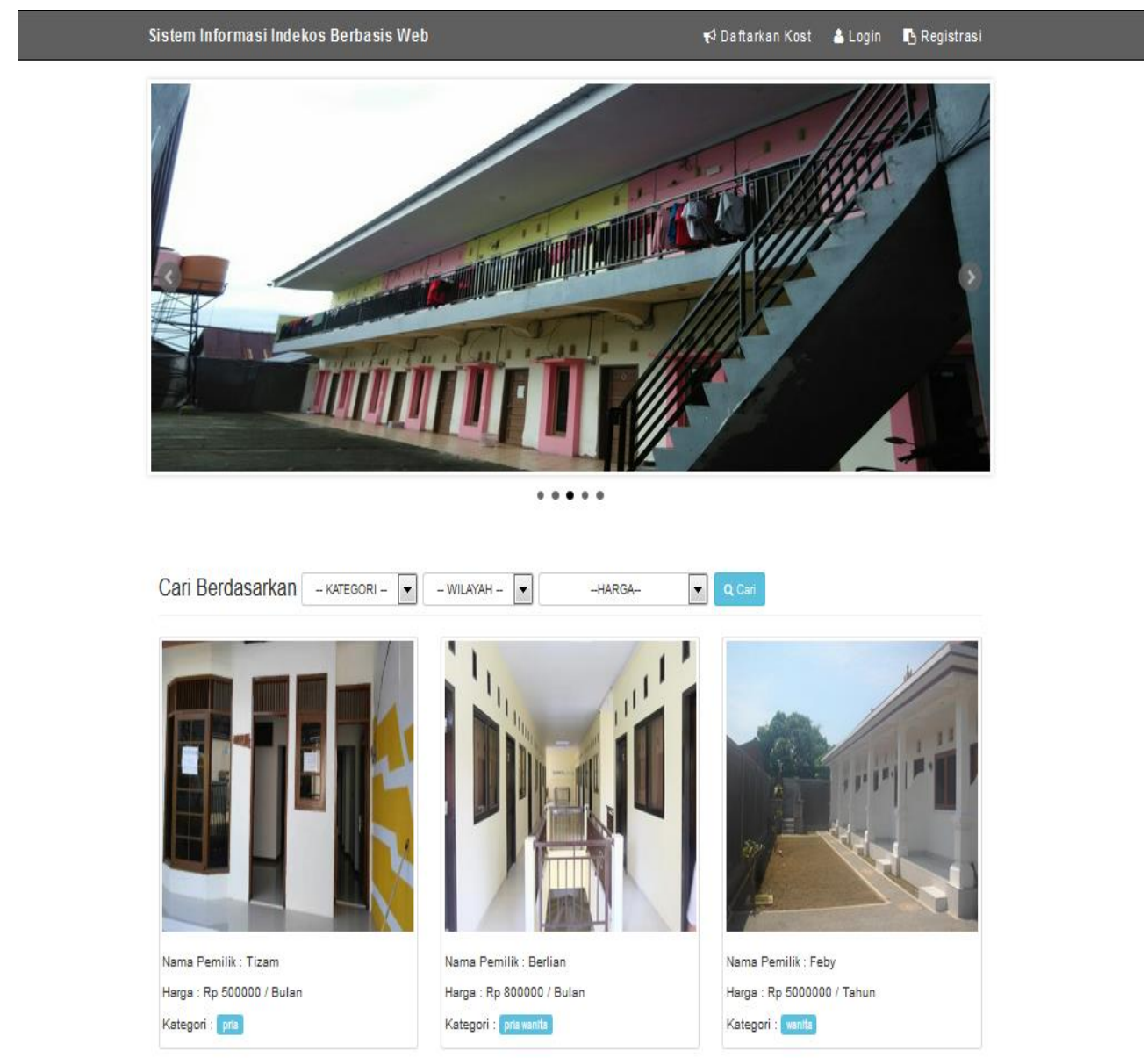

Gambar 5. Halaman Home

b) Halaman Lihat Detail Profil Indekos
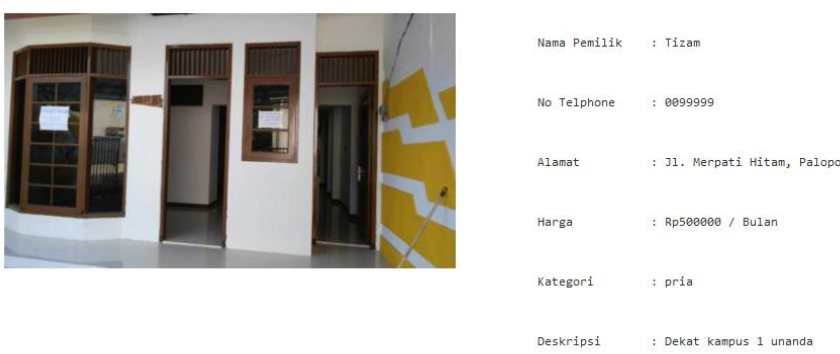

Gambar 6. Halaman lihat detail profil indekos 
c) Halaman Cara Daftar Indekos

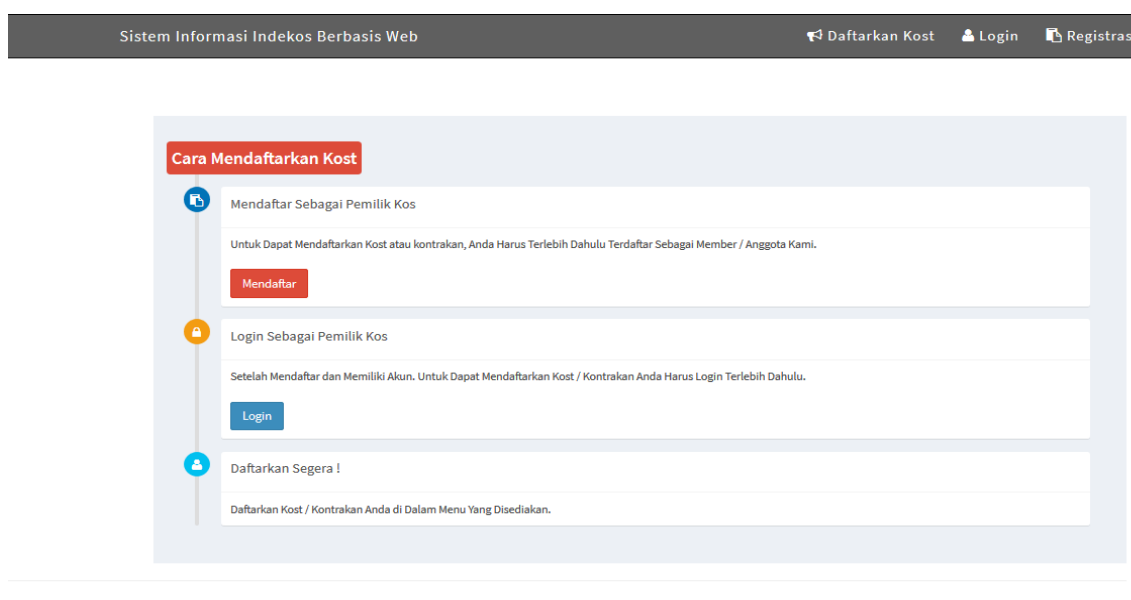

Gambar 7. Halaman cara daftar indekos

d) Halaman Registrasi Pemilik Indekos

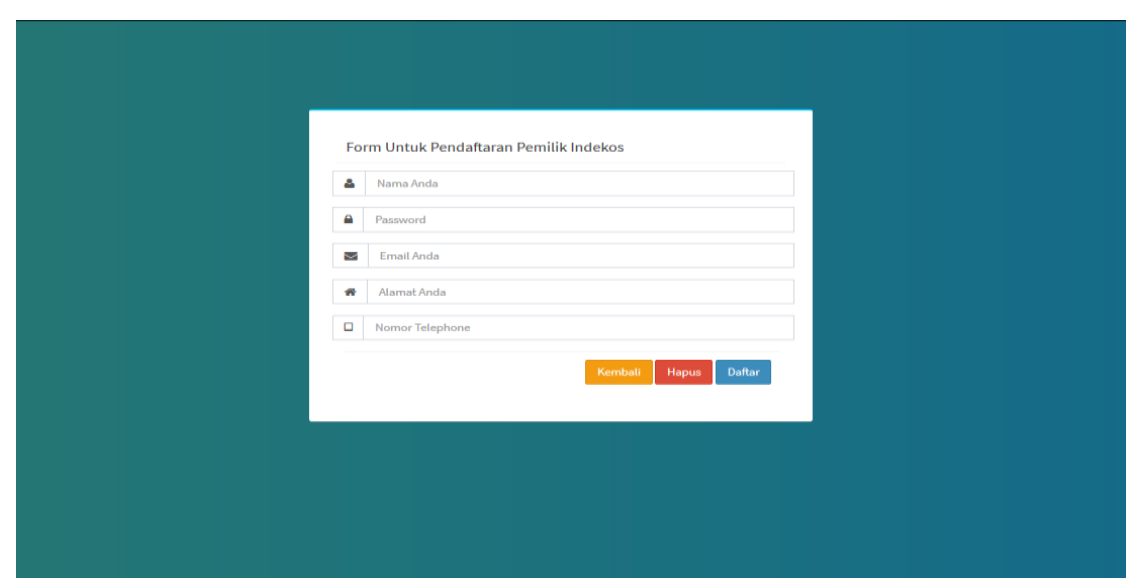

Gambar 7. Halaman registrasi pemilik indekos

e) Halaman Beranda Pemilik Indekos

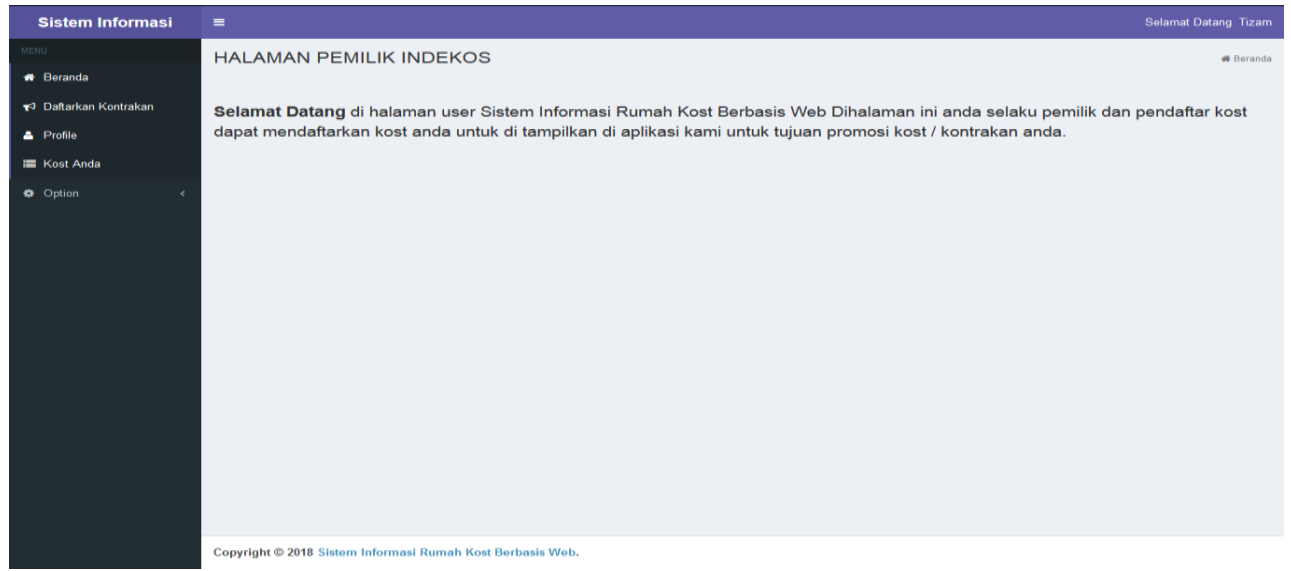

Gambar 8. Halaman beranda pemilik indekos 
f) Halaman Home Admin

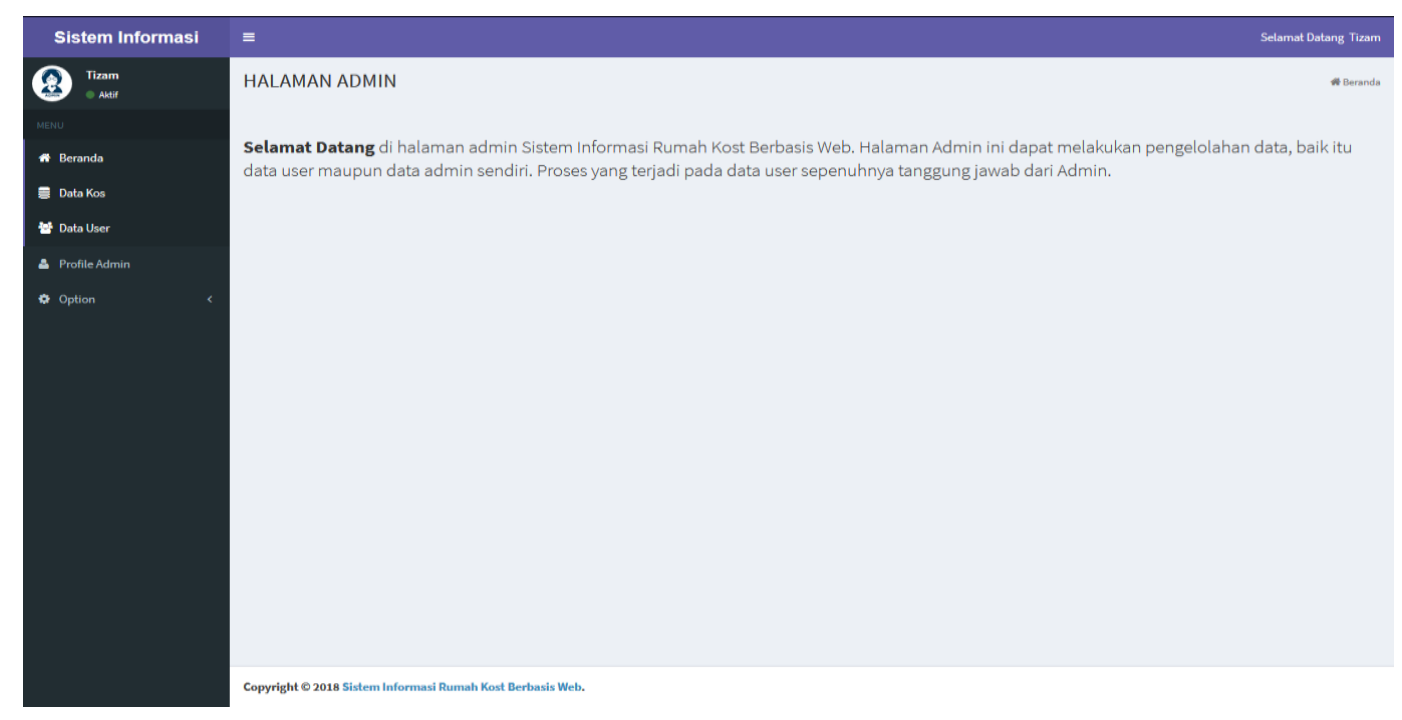

Gambar 9. Halaman home admin

\section{KESIMPULAN}

Berdasarkan hasil dan pembahasan di atas, maka dapat diperoleh kesimpulan bahwa sistem informasi indekos berbasis web ini dapat mendukung masyarakat dalam mengakses dan memberi informasi indekos yang diinginkan baik dari sisi pencari indekos atau penyedia indekos itu sendiri. Adapun cara mengakses sistem informasi indekos ini melalui alamat website https://sisfokost.000webhostapp. com/.

\section{DAFTAR PUSTAKA}

Dadi Rosadi, F.O. (Juni 2016). Aplikasi Sitem Informasi Pencarian Tempat Kost di Kota Bandung Berbasis Android. Jurnal Computech dan Bisnis, Vol.10, No.1, ISSN: 2442-4943.

Didit Gunawan, R.R. (Juni 2016). Sistem Informasi Sewa Rumah Kost dan Rumah. Jurnal Ilmiah Go Infotech Volume 22 No. 1, ISSN: 1693-590x.

Fitri Damayanti, H. (2016). Sistem Informasi Rumah Kost Berbasis Web dan Google Maps Api. Jurnal Ilmiah Multitek Indonesia, Vol.10, No.1, ISSN: 1907-6223.

Handy Hanjaya, D. J. (2013). Aplikasi Sistem Informasi Real Estate PT. Greenhouse. Jurnal Sistem Informasi, Vol.8, No.2, 113-124.

Harri Singgih Pratikto, S. E. (2014). Sistem Pencarian dan Pemesanan Rumah Kost menggunakan Sistem Informasi Geografis (SIG). Jurnal SCRIPT, Vol.1, No.2, ISSN: 2338-6304.

Kristiyanto, R. D. (2017). Aplikasi Pemilihan Tempat Kost menggunakan Google Map Api dengan Metode Weighted Product. Yogyakarta: Program Studi Teknik Informatika Jurusan Teknik Informatika Fakultas Sains dan Teknologi Universitas Sanata Dharma Yogykarta.

Putri, A. S. (2012). Info Kost Online Terintegrasi. Surakarta: Teknik Informatika Fakultas Matematika dan Ilmu Pengetahuan Alam Universitas Sebelas Maret.

Rachmadi, A. (2013). Sistem Informasi Rumah Kost Berbasis Web di Yogyakarta. Yogyakarta: Program Studi Teknik Informatika Fakultas Sains dan Teknologi Universitas Sunan Kalijaga. 
Riadiana, I. F. (2014). Sistem Informasi Rumah Kost Berbasis Web: Studi Kasus pada Rumah Kost "Hero" Yogyakarta. Bandung: Program Studi Teknik Informasi Fakultas Teknik Universitas Widyatama Bandung.

Rini Indriati, P. K. (2017). Sistem Bantu Pemilihan Rumah Kost dengan Weighted Product dan Geographic Information System. Politeknosains, Vol.XVI, No 1, ISSN 1829-6181

Setiawan, R. D. (2017). Alikasi Sistem Informasi Kost Berbasis Android. Surakarta: Program Studi Teknik Elektro Fakultas Teknik Universitas Muhammadiyah Surakarta.

Simanjuntak, E. (2013). Sistem Informasi Pemasaran Berbasis Website pada PT. Trimmitra sebagai Sarana Penjualan Produk secara Online. Jawa Timur: Fakultas Teknologi Industri Program Studi Sistem Informasi Universitas Pembangunan Nasional "Veteran" Jatim. 